This is the Accepted Version of an article which is published by Oxford University Press on 17 June 2016 in London Review of International Law. Please refer to the published version when citing and to any applicable terms of use of the publisher. Article available at: http://Iril.oxfordjournals.org/content/by/year

Accepted Version downloaded from SOAS Research Online: http://eprints.soas.ac.uk/22628

\title{
From performativity to the material culture of legal expertise? Ben Fine*
}

It is with some trepidation that I engage with this book, ${ }^{1}$ feeling like a fish out of water, trespassing where I have no right to be, and embracing any number of other metaphors to express engaging with the discipline of law from the perspective of political economy. Whilst I am committed to interdisciplinarity and have some record in my own research in this respect, ${ }^{2}$ it is limited in the case of law. And I am wise enough to know that having a feel for a discipline, both its presences and omissions, is an extremely demanding skill that cannot be gained either lightly or quickly.

Such hesitations amplify given this is a grand book, not least in scale and scope. It seeks to redefine the field of international law in the context of global political economy. It inevitably raises much with which any reader is liable to agree, disagree or remain uncertain, partly because of the inevitable limitations of space for supportive evidence whether through argument or case study. In this light, my goal is to seek to be constructive, even if with considerable modesty as well as caution, drawing upon the book's substance, adding to it and suggesting alternative or additional framings. In short, I view the book through the lens of political economy and economics, and my familiarity with them, as opposed to those who are better placed to appreciate how the book views and contributes from within the discipline of international law albeit attached to its own interdisciplinarities.

I begin in the next section by offering a critical commentary on the performativity thesiswhich seems to be a starting point for the book—not least because performativity has recently flourished within economics. As Brett Christophers has put it, whilst:

the burgeoning and very much contemporary literature on the so-called 'performativity' of economics . . . comes in many shapes and sizes, the central gist of the bulk of this literature has been that economics plays an active rather than purely passive role in the economy. Economists and economic statisticians, and the economic ideas, models and measurements they produce, do not merely describe an 'external' economic reality; they are always and everywhere part of the economy, shaping and reproducing it in the very moment that they attempt to capture it conceptually. In the words of one of the main protagonists in this field, Donald

\footnotetext{
* Professor of Economics, SOAS, University of London. Email: bf@soas.ac.uk. Thanks for comments from the symposium and especially from Stephen Humphreys and referees on earlier drafts.

${ }^{1} \mathrm{D}$ Kennedy, A World of Struggle: How Power, Law, and Expertise Shape Global Political Economy (Princeton UP, 2016).

${ }^{2}$ Most obviously in work on 'economics imperialism'. See especially B Fine \& D Milonakis, From Economics Imperialism to Freakonomics: The Shifting Boundaries Between Economics and Other Social Sciences (Routledge, 2009) and D Milonakis \& B Fine, From Political Economy to Economics: Method, the Social and the Historical in the Evolution of Economic Theory (Routledge, 2009).
} 
MacKenzie, economics is 'effectively performative' since it is 'an active force transforming its environment, not a camera passively recording it'. ${ }^{3}$

No doubt, legal experts make the law just as economists make the economy (and transgress one another's makings). But, the performativity paradigm for economics has increasingly undermined if not dissolved itself the more it has been applied. The same appears to be unconsciously true in microcosm of Kennedy's book as it unfolds. But showing this below is not an entirely negative exercise as insights are gleaned into how we can go about situating the role of experts, legal or otherwise, in the making and justifying (or offering critique) of the global political economy. In part, this requires an account of globalised, financialised neoliberalism as the context within which experts rule, or are ruled. This is addressed in a section that begins to frame how to approach the material culture of expertise and, in the following section, is developed further and brought to bear upon the issue of the reregulation of finance (or not).

\section{PERFORMATIVITY MISRULES OK?}

I have taken the book's main thrust as suggesting that international law is made by international legal scholarship, and/or by international legal experts in particular. For, 'International law today is an extremely plural and contingent field that combines a diverse technical practice with a multiplicity of orienting theories about how international law works and where it is going. What holds it all together is a kind of professional faith'. ${ }^{4}$ However, 'the ways power operates across the world remain obscure. The missing piece, I've come to believe, is the way expert ideas and professional practices of assertion and argument construct and reproduce a world of inequality and injustice. In world affairs, expertise is the coin of the realm. ${ }^{5}$ It is, however, complemented by a method emphasising how such legality is embedded in the situated role of expertise, and how it appears to and through experts themselves as they go about their practices. As a result, the approach aims, "[ $t$ ]o focus on the middle space between big systems and ethnographic study'. ${ }^{6}$ In particular,

[t]he objective is to evoke the world as they [the experts] see and create it and articulate pathways through which this work could be impactful without adjudicating their own claims to influence in one or another situation.

In this light, it is hardly surprising that there is explicit flagging by Kennedy to the mast of the performativity hypothesis, not least in wishing to avoid a 'systemic logic'. ${ }^{8} \mathrm{He}$ observes:

\footnotetext{
${ }^{3}$ B Christophers, Banking Across Boundaries: Placing Finance in Capitalism (Wiley-Blackwell, 2013) 9. From my perspective, Christophers correctly observes, from his superb study of how (international) finance had been 'made' productive (i.e. included as value producing in national statistics), that 'there is a capitalist system, increasingly structured by markets, with a history certainly sculpted in part by economic discourses and their instantiation in different calculative technologies, but the dynamics of which are clearly irreducible to those ideas and indeed represent an ineluctable framework for comprehending those ideas and their potential significance'. Ibid 11-12.

${ }^{4}$ Kennedy (2016) 12.

${ }^{5}$ Ibid 14 (emphasis added).

${ }^{6}$ Ibid 4.

${ }^{7}$ Ibid 124. This is immediately preceded by: 'Nor is my objective to formulate hypotheses that could be proven in the social scientific sense of demonstrating cause and effect. It is very unlikely that one could prove the impact of professional ideas in this sense. Efforts to do so risk narrowing the inquiry too sharply to be of much explanatory power. Moreover, arguing about effect is one of the most prevalent activities through which experts pursue their projects.' This raises issues of how strong is explanation without cause and effect (and leaves open whether setting it aside distances Kennedy himself from being an 'expert').
} 
The work that lies closest to my own preoccupations stresses the performative dimension of expert practice: expert work constituting the space of its own expertise. Economists, for example, do not merely study markets, they 'make' them by articulating what markets are and how they function. ${ }^{9}$

Kennedy is seeking to do for law then what MacKenzie's justifiably and still classic contribution, An Engine not a Camera, has (or has not) done for economics. ${ }^{10}$ I reject this venture from the following perspectives. First, I have been totally opposed to the performativity thesis from an early exposure to its embryonic form as Actor-Network Theory, what I called 'Callonistics'. ${ }^{11}$ Its main idea that economists make the economy borders between the nonsensical and the tautological, not least as the vast majority of economics is itself nonsense and so far removed from economic realities as to be useless for practical purposes. ${ }^{12}$ Consider the story of the Head of the UK Government's Economic Service, which employs 1700 economists, who opened a conference rapidly convened to discuss the relevance of Keynes in the wake of the Global Financial Crisis, and attended by 200 of the latest recruits who had presumably only ever lived and learned under monetarism/ neoliberalism. In the wake of policy and consequent intellectual panic, our chief policymaking economist bemoaned the fact that there was no economic theory that he knew that was of any use in his predicament but that whatever advice he gave he knew would have to be framed in the language of expert orthodoxy despite its universally recognised deficiencies. And, bail out the banks with limited reregulation (see later) has been the major response. Now, from where did that performativity come in making markets, not least in terms of what quantitative easing did for financial institutions?

Second, it is difficult to be certain that the foregoing is no more than a parody of the performativity paradigm, in part because it seems less than legible to some of those who are not its practitioners and, in part, because it enjoys (or suffers) varieties of evolving interpretations and refinements (or backtrackings). When the distinction between the making of markets and the production of meanings about markets is dissolved - and by suggesting that they occur simultaneously - the causal relations between the two are likewise dissolved, leading to a universalised vocabulary to bridge the relations involved, deploying notions of 'framing', 'leaks', the 'processual', 'entanglement', 'disentanglement', 'counterperformativity', 'overflowing' as well as 'economization'. ${ }^{13}$ In discarding reliance upon social structures, are they not substituted by an ever-expanding set of more or less arbitrary universals (or, at the other extreme, a flight to more or less detailed context; see later discussion)? Significantly, Wullweber, in sympathy with the performativity project, identifies two different strands in the literature, which he dubs the micro and macro approaches and

\footnotetext{
${ }^{8}$ Ibid 7.

${ }^{9}$ Ibid 4.

${ }^{10}$ D MacKenzie, An Engine, Not a Camera: How Financial Models Shape Markets (MIT Press, 2008).

${ }^{11}$ See the classic M Callon (ed.), Laws of the Markets (Wiley, 1998) and, for critique, B Fine, 'Callonistics: A Disentanglement' 32(3) Economy and Society (2003) 478.

${ }^{12}$ Although this is not to deny that nonsense may inform policymaking but which, why, when and how and for whom remain germane.

${ }^{13}$ These terms taken from B Braun, 'From Performativity to Political Economy: Index

Investing, ETFs and Asset Manager Capitalism' 21(3) New Political Economy (2016) 257, which also offers an excellent overview of the performativity trajectory from a favourable posture.
} 
which derive from a focus on (individual) agency and structure, respectively, leaving open how the two can be combined whilst restoring social structures in the form of the macro! ${ }^{14}$

But what of the case of MacKenzie, the strongest example of the performativity thesis within economics. Did expert scholarship make the markets? Do we really believe that the prodigious expansion of financial markets over the last thirty years (raising the ratio of global financial assets to GDP by three times) is in major part the simple consequence of the ability of economists to be able to find formulae for pricing complex derivatives, the most prominent being the Black-Scholes formula for trading in the derivatives known as options? Quite apart from the BS formula itself being based on a set of assumptions so far removed from reality that it was equally surely far from the mind of our Chief Economist when trying to perform in the wake of the consequences of its application, let alone from the minds of traders themselves as they mercilessly and deceptively pushed sub-prime or whatever.

In short, even if we accept that markets must be conceptualised before they can be made (as Marx says of human as opposed to beehive production), there are many more determinants involved than the conception itself however important it might be - and there will be examples of ex post facto - or even an absence of - conceptualisation for many traders (or others), who 'just do it'. This places us back in the realm of the evolving context for performance, a place which performativity takes for granted or at best relies upon as an evolving chain of individualised actions.

So what is at issue is not whether agents and their constructs have effects but how to situate them, with performativity unduly dismissing social structures, how these are conceived, and the causal role of structures themselves. In this light, MacKenzie himself, if possibly unwittingly, offers a rather different example of the servile role of financial economics in its relationship to financial markets and targeted by a movement for a professional ethics to be established for academic economists who publish the findings of their research without revealing the sources of their paymasters. ${ }^{15}$ In the early 1970s, George Schulz (erstwhile Dean of the University of Chicago's Business School) commissioned, for a mere $\$ 5000$, his colleague Milton Friedman to write a report to recommend allowing the first ever futures foreign currency market to complement those for pork bellies.

The rest, as it were, is history but this is surely a case of the market making the, admittedly ripe and ready neoliberal, economist rather than vice-versa. Or if we trace from Friedman through Schulz, to the traders and so on, we end up needing to explain the structures and dynamics of the US economy. And, whilst performativity (even if it is not alone in this) rightly emphasises that different markets are made differently (not least prior to exchange itself in terms of how different things are produced and distributed in becoming commodities), it is equally important to identify both historically and structurally what differentiated markets share in common as the basis for understanding their differences. Otherwise, we have no conception of the economy other than as a set of differentiated markets that are as

\footnotetext{
${ }^{14} \mathrm{~J}$ Wullweber, 'Performative Global Finance: Bridging Micro and Macro Approaches with a Stratified Perspective' 21(3) New Political Economy (2016) 305.

${ }^{15}$ See G Epstein \& J Carrick-Hagenbarth, 'Dangerous Interconnectedness: Economists' Conflicts of Interest, Ideology and Financial Crisis' 36(1) Cambridge Journal of Economics (2012) 43, and, in the context of performativity, P Mirowski \& E Nik-Khah, 'Markets Made Flesh: Performativity, and a Problem in Science Studies, Augmented with Consideration of the FCC Auctions', in D MacKenzie, F Muniesa \& L Siu (eds), Do Economists Make Markets? On the Performativity of Economics (Princeton UP, 2007) 190.
} 
distinct as, say, languages (whether these be made by expert linguistics or otherwise - after all, we need experts to tell us when a dialect is just that or a distinct language!).

Now, I am not saying this is a simple issue as the relationship across scholarship, discourse and practice is complex and needs to be unpicked, which I discuss later. For the moment, though, I highlight two crucial properties of the performativity thesis applied to economics. The first is, apart from MacKenzie himself, it scarcely has a presence. Where are the studies establishing the making of the economy by economists? Further, whilst the orthodoxy is rightly infamous for its intolerance and lack of diversity or pluralism, even the books apparently favoured by the Joe Stiglitzes and Paul Krugmans of the world, let alone the Amartya Sens, cannot be shown to have had more than a smidge of influence on the making of the markets as opposed to the discourses through which they are interpreted. As, for example, my colleague Elisa Van Waeyenberge has shown, the result of the much heralded post-Washington Consensus (which, alongside neoliberalism of which it is a part, not an opposition, is arguably misread by Kennedy's book (see below)) was to strengthen the hold of the Washington Consensus over the allocation of World Bank aid. Stiglitz, after all, was sacked from the World Bank once he tried to take his legitimising scholarly role into the world of policymaking, with Larry Summers, a leading beneficiary of financial largesse, delivering his notice. ${ }^{16}$

To be fair, the performativity thesis does not fall simple because some, even most, of those who would make the economy, fail to do so in the images of their models. But it is not within their ideas and their origins that we can explain who and who does not get to have the purchase, to coin a phrase, over the makings and thereby exert their expertise. Nor, I must emphasise, am I simply turning performativity upside-down and suggesting that economists merely serve as the more or less ideological, reflective or deluded agents of the economy, or economic interests, although this often proves a useful starting point as does the observation that such economics tends to change in response to, rather than make, circumstances as can be charted, for example, at least in part for the World Bank in its making of markets. ${ }^{17}$ Indeed, ambiguity around performativity has been acknowledged, quite apart from a dearth of case studies, through allowing for stronger or weaker forms of the thesis. This raises the question of how weak does weak have to get before it no longer exists, not least as we will always find that scholars, experts or the like (themselves sufficiently wide-ranging, especially in the legal field let alone economics when it is often extended to include accountants, traders, and so on) are inevitably discursively responsible for their fields. Traders make trade just as some lawyers make the laws, except when they don't and some others steal or break the law.

Clearly, in most activities, there will be layers of agents and agencies - from framing experts to humble practitioners if not victims. But how they are causally positioned in relation to one another cannot be pre-determined (think nuclear physicists as opposed to ministers of defence) nor mutually determined. It seems as if such indeterminacy is resolved by the performativity paradigm by reducing it to amorphous notions of context which, in effect, serve as surrogacy for discarded social structures lest the latter become too heavily present.

\section{FROM ECONOMICS TO LAW}

Enough already on the lack of performativity of economics. But what is striking about the book, as far as the performativity thesis is concerned, is that it does undertake, however

\footnotetext{
${ }^{16}$ See hers and other essays in K Bayliss, B Fine \& E Van Waeyenberge (eds), The Political Economy of Development: The World Bank, Neoliberalism and Development Research (Pluto, 2011).

${ }^{17}$ Ibid.
} 
consciously, a trajectory from strong to weak, dwindling forms in arguing for the determining role played by experts, traversing many of the issues already raised. It remains ambiguous whether social structures are being put in their place or being rejected altogether. Thus, if unduly favouring orthodox social science:

The tools of neoclassical and institutional economics, international relations theory, systems theory, public choice and game theory, or strategic studies are crucial for understanding the dynamics of global political economy. By focusing first on the powers, vulnerabilities, and strategies of people with projects in struggle with one another, however, I aim to compensate for some classic limitations of the actor/structure/system framework. The most crucial for my purposes are the tendency to reify the actors and structures one sees, a bias toward order, and the potential to overlook the knowledge work of experts with the result that their shared logic is treated as the logic of the system itself. ${ }^{18}$

This appears under the heading, 'Cartography as an Antidote to the Limits of System Analysis' - but is it antidote or disposal? This remains unresolved. And, ambiguity likewise surrounds the question of whether the system has to go altogether or whether its logic needs merely to be supplemented to allow for proper consideration of the hypothesised role of expertise:

A significant drawback of the actor/structure/system framework in social scientific work is the tendency to treat expertise as a marginal part of the story, relevant only when expert ideas capture the will of system actors or the technocratic process torques the system's routine operations. ${ }^{19}$

In short, Kennedy essentially draws upon both micro and macro performativity or the like as it suits and, in any case, might reasonably be interpreted to retain the role of structural factors, not least as he draws upon diagrammatic representation of various structures on at least a dozen or more occasions. Indeed, he sees, '[i]n short, the disconnection of economic and political life threatens the sustainability of contemporary political and economic structures ${ }^{20}$ whilst accepting that, 'Understanding of position of expertise is highly structured . . . across global and national, the inherited and the commonsense'. ${ }^{21}$ So structures do prevail, at least condition, and are subject to threat. If so, in what sense and to what extent do such structures perform rather than legal experts?

Another aspect of Kennedy's over-ripe performativity is the use of what might be termed universals of fascinating if ambiguous origins, whether derived through empirical regularities (and personal experience) or analytical construction. Thus, apart from (global) legalisation itself, there is the distinction between the background of decisive experts and the foreground

\footnotetext{
${ }^{18}$ Kennedy (2016) 75.

${ }^{19}$ Ibid 82. See also ibid 59: 'Placing struggle rather than system at the center of the story encourages opposing interests to be identified and the costs and benefits of alternative projects to be assessed'. Again is system being downgraded or rejected? I leave aside the issue of the distinction between system and structure although, presumably, you could have one without the other. I take up the issue of struggle later.

${ }^{20}$ Ibid 26. Even so, 'The global political and economic arrangements that result are surprisingly sturdy for all the talk of crisis and worry over sustainability'. Ibid 31.

${ }^{21}$ Ibid 32 (emphasis added).
} 
of practice. Kennedy argues that, '[w] hen background work has been most successful, it is very difficult to see', 22 and, furthermore:

Experts rule by argument and assertion. In whatever settings they work—advising diplomats, advocating development loans, or denouncing governments - experts bring their expertise to bear by articulation. ${ }^{23}$

We have scattered references to insiders and outsiders, order and disorder, plasticity, as well as to the idea that 'Governments everywhere are weak'. ${ }^{24}$ There is also the suggestion that:

The dispersion of struggle has increased the significance of professional and quasiprofessional modes of engagement that communicate transnationally, retain sufficient status to be effective, and are themselves uncertain and fragmented enough to sustain multiple insistent projects simultaneously. ${ }^{25}$

And a further ambiguity arising out of performativity as it is stretched to, or beyond, breaking point is in pinning down who are (legal) experts and which of these count. One aspect of this is how widely the caste of experts is cast, something that does itself need to be closely specified with boundaries drawn and across who does what and how-involving, just for law itself, academics, judges, lawyers, regulators, police, the army, state apparatuses, international organisations, etc.

But there is also the role of non-legal agencies, not least because, 'legal practice has been a joint product of economic and political ideas and expert work'. ${ }^{26}$ Indeed, 'In the contemporary world, expertise and the practices of experts have merged with the calculations of economic and political actors, ${ }^{27}$ so much so that:

Different modes of expertise jostle with one another to define and manage aspects of global life: the public analytics of government and the private logics of commercial activity; the political vernacular of international relations and the economic models of global markets and finance. The ubiquity of law as a medium of struggle across many domains makes it a good place to begin, but the same could be said for economics or science and technology and many other domains of expert work. ${ }^{28}$

And another inevitable aspect is the competition/conflict and/or alliances for influence within and across these expert(ise)s. It is suggested that, 'Governance by expertise is rule through ruthless struggle among experts who have retained their faith and expanded their jobs' $;{ }^{29}$ 'The knowledge practices of experts are undertaken through conflict and struggle that are

\footnotetext{
${ }^{22}$ Ibid 116. Indeed, 'My hypothesis is that this stability [of global political and economic arrangements] arises from the relative invisibility and imperviousness of the world of technical management to contestation' (ibid 32), not least as, 'the work of the background has colonized the foreground and the context' (ibid 119).

${ }^{23}$ Ibid 135 (emphasis added).

${ }^{24}$ Ibid 26.

${ }^{25}$ Ibid 51 (emphasis added).

${ }^{26}$ Ibid.

${ }^{27}$ Ibid 55

${ }^{28}$ Ibid 12 .

${ }^{29}$ Ibid 20.
} 
ruthless, unceasing and often violent'; 'Expertise is special knowledge made real as authority in struggle'; ${ }^{31}$ and 'Background work is a plural and contested activity'.

Thus, whilst, on the face of it, the idea that international law is subject to social Construction $^{33}$ by expertise is consistent even with a strong form of performativity, this depends upon how the 'social' and the Construction are interpreted and, as suggested, they are ultimately extremely weak within Kennedy's account. For example, in the book, social Construction is endowed with legal experts as backgrounding the framing of decision-making with the former, presumably being the ultimate determinant. It involves inter- and intradisciplinary contributions, across topics as diverse as religion, ideology, ethics, norms, institutions, distribution, development and force, with considerable flexibility, discretion and the exercise of power. It follows, and appears openly accepted, that international law is not only subject to Construal by experts and others but Contested even if Closed in some respects to all but a few (the background of Collective experts). Experts bring order to disorder especially as struggles are (exaggeratedly?) fragmented and dispersed under neoliberalism:

The dispersion of struggle has increased the significance of professional and quasiprofessional modes of engagement that communicate transnationally, retain sufficient status to be effective, and are themselves uncertain and fragmented enough to sustain multiple insistent projects simultaneously. ${ }^{34}$

But it is a Chaotic (dis)ordering of expert(ise)s. ${ }^{35}$ For whilst, 'Theirs is an ecumenical, eclectic, and disenchanted faith. It is also astonishingly appealing: at once practical and promising, recognizing the world as it is with its eyes firmly planted on the world to come', ${ }^{36}$ and, 'Working for law requires a suspension of disbelief in law's dark potential'. ${ }^{37}$ As a result:

Well-meaning experts routinely go terribly wrong, from the 'best and brightest' in Vietnam through the planning and execution of the recent wars in Afghanistan and Iraq. Human rights activists, development planners, and international lawyers all have blind spots and biases, overestimate their insight, enchant the tools they have learned to use, and place faith in their discipline's potential above careful assessment of its accomplishments. They have learned to see order and system in the world rather than struggle, and too often experience their expertise as clear and persuasive, underestimating the plasticity, ambivalence, and conflicted nature of what they know. $^{38}$

\footnotetext{
${ }^{30}$ Ibid 54.

${ }^{31}$ Ibid 108.

32 Ibid 120.

${ }^{33}$ The reason for the capital letter here and those that follow will emerge later but see B Fine, 'Consumption Matters' 13(2) Ephemera (2013) 217.

${ }^{34}$ Kennedy (2016) 38.

${ }^{35}$ Further: 'It is also common to overestimate the rigor of expert analytics. Ideas and analytics rarely dictate results. Experts disagree sharply with one another and are only too aware of the gaps, conflicts, and ambiguities in their analytics. Their work in law and policy is more argument and assertion than reason. Expert work is positioned and strategic, a matter of posturing as much as persuading.' Ibid 3.

${ }^{36}$ Ibid 20.

37 Ibid 246.

${ }^{38}$ Ibid 277.
} 
Ultimately, however, expertise comes to accept its role, even if Conforming to principles, practices and precedents in both observance, and breach. ${ }^{39}$ For:

The puzzle is how so much struggle fades from view as experts embody the voice of reason and outcomes are assimilated as facts rather than contestable choices. I am interested in the way experts forget their struggles and their role in distribution to celebrate their knowledge as universal, their world as ordered, their path forward aligned with progress. Modern expertise knows and it forgets - or refuses to knowits powers and its limits. When they forget - and we forget - it becomes all the more difficult to understand how this world, with all its injustice and suffering, has been made and reproduced. And more difficult to identify levers of change or experience the place we stand as a fulcrum of possibility. The result of continuous struggle is an eerie stability it is hard to imagine challenging or changing. ${ }^{40}$

Much emphasis is placed upon the global political economy as attending to distribution, itself highly Commodified and subject to corresponding monetary calculation. International law would appear to be underpinned by a multiplicity of Contradictory forces, necessarily made in specific Contexts:

To understand how experts govern - how they develop and deploy their expertise, how they struggle and reason with one another, and how their knowledge comes to be taken up by others - we need field-and site-specific studies alongside work on patterns of struggle among experts and expert communities. ${ }^{41}$

Grounding international law, and the role of experts, within and across these factors does, I suspect, leave the performativity thesis for international law in much the same state as for economics, undermining itself the more it is applied. But there are also two differences, at least in practice, compared to the exemplary case of MacKenzie from economics. One is that more detail would be necessary. To sustain the argument, that experts create the law, one would need to establish how those experts do so, with what substance, how their own conflicts are internally let alone externally resolved, and thus trace the complicated, long and recurring trajectory from their own internal, contextualised debates to their practical application in the court of life, the fighting of wars, the provision of protection and basic needs, and the settlement of trade disputes. Surely, if we were to pursue the performativity thesis, there would be differences in the where, the what, the how and the who of the role of experts depending upon the sphere of international law. This is itself sufficient to suggest that experts themselves are not always and uniformly decisive since their diversity would be similarly contingent upon the sphere of application and context. No doubt Kennedy would agree but such specifications are contingent upon social structures.

Possibly, the demand for more detail and specificity in the workings of and through expertise is a reflection of my profound lack of knowledge of law. It may be enough for the scholars of law to be offered a marker by which a cascade of evidence and argument can be taken for granted. ' 1648 ' for example has a chapter title dedicated to it and appears countlessly throughout the text. It obviously means a great deal to legal scholarship but it surely demands clearer argumentation and its relevance needs to be filled out for the contemporary relevance of over 350 years later. In short, are the same (sorts of) experts decisive to the same extent, in

\footnotetext{
${ }^{39}$ Ibid $173-74$.

${ }^{40}$ Ibid 5.

${ }^{41}$ Ibid 120.
} 
the same way, irrespective of the nature both of the field of (international) law and the nature of the other experts at hand. On the other hand, this may be indicative of another aspect of the omission of detailed case study, universalism and lack of historical specificity especially for the contemporary period. If expertise is the key to international law, when did it become so, and is it unique to international as opposed to national or other law, quite apart from its variation across different areas of application? There are fields in which expert scholarship does not prevail, with social policy (with Scandinavia as the golden goal) and climate change (mitigation) as obvious examples, but no doubt these are simply the wrong experts, in the wrong place at the wrong time.

\section{FINANCIALISED NEOLIBERALISM AS CONTEXT?}

Such reflections open the opportunity for me to be more constructive in (re)framing the role of experts in performing international law. I do so through the prism of material culture though I am cautious about extrapolating my own work in different areas onto this topic. But it is in these areas, ranging across consumption, financialisation, ethics, public provision and so on, that we need to confront the problem of how the material and the cultural (including scholarship and expertise) intersect and mutually condition one another.

In this vein, let me begin with some propositions concerning contemporary capitalism which surely condition the context within which international law is currently made. This is necessary given that, as Kennedy suggests, governments are, 'buffeted by economic forces, captured by economic interests, and engaged [in] their own economic pursuits. Meanwhile, unmoored from stable political management, the global economy has become volatile and destructive, veering from boom to bust, set free from the stabilising hand of sound regulatory management' ${ }^{42}$ If further, as Kennedy argues, the global (political economy or otherwise) is subject to 'legalisation', ${ }^{43}$ we might ask what exactly is being legalised?

Here, reference to both neoliberalism and globalisation needs to be more closely specified. ${ }^{44}$ Neoliberalism is a heavily used term, if scarcely appearing in the book itself. It often serves as an expression of abuse or dislike for particular developments or policies. Its origins lie with the Reaganism and Thatcherism of the early 1980s, and it has become especially associated with cuts in wages and welfare, privatisation, supposed promotion of the market at the expense of the state, and general hostility to the working class and its and other progressive organisations. However, over the past thirty years, neoliberalism has displayed considerable variation as a phase of capitalism, ranging in practice across three highly differentiated elements by time, place and issue (or context taking these together) - according to how ideology, scholarship and policy in practice are combined, rarely consistently. For example, and most obviously, the financial crisis gave rise to huge state intervention on an unprecedented scale in support of the financial system - the (false) posture of leaving things to the market was rapidly abandoned as the supposedly deregulated financial system exploded.

Crucially, then, and not just around finance, neoliberalism is not about the withdrawal of state (economic) intervention. It has always been associated with a strong not a weak state, and an

\footnotetext{
42 Ibid 27.

${ }^{43}$ Ibid 4-5.

${ }^{44}$ What follows draws heavily upon a whole range of work but for much of this gathered together, especially forging links between financialisation and neoliberalism, and the substance of each, see K Bayliss, B Fine, M Robertson \& A Saad-Filho, 'Thirteen Things You Need to Know about Neoliberalism', Thematic Paper, 2015, available at http://www.networkideas.org/focus/jan2016/pdf/Thirteen Things.pdf (last visited 14 April 2016).
} 
authoritarian one, as opposed to promoting personal liberties, despite its ideology. Indeed, the distinguishing role of the (advanced) neoliberal state has primarily been to promote the interests and internationalisation of capital in general and of finance in particular. This has had major influences on the nature of economic and social restructuring, not least as these are attached to financialisation as the lever of ownership and control of productive and other forms capital as the means to appropriate surplus. This is not to reduce neoliberalism to financialisation although it is at its economic core, with correspondingly profound and increasing implications for most aspects of economic and social life.

As a result, the neoliberal state does disembed certain practices as Kennedy's book suggests but, equally, it embeds others, whether formal or informal, for which shifts in the balances, locations, forms and consolidation of power are paramount. With this, however, the dispersion and disorganisation of struggle, a key characteristic of neoliberalism as Kennedy acknowledges, does not necessarily strengthen the role of experts as hypothesised. Rather, it concentrates power in those whose presence can be found across the (newly-formed) corridors of influence with or without revolving doors, through the media, and access to politicians and bureaucrats at national and international levels as well as, of course, legal expertise.

This is not the place to digress on the nature of financialisation and neoliberalism with, it should be added, corresponding implications for how we understand global political economy. Equally relevant are the political imperatives of the United States on the world stage. This might currently be summed up as establishing the right to intervene (militarily) wherever it chooses with, presumably, sharp differences with the Cold War period and corresponding configurations of international law across each and every aspect from military intervention itself through to the pursuit, or denial of, human rights in both theory and practice.

To put it bluntly, the US has the powers and the (expert) lawyers to reflect and to pursue its interests, whomsoever may define these and how. None of this can be a monopoly, let alone a hegemony, of the (US expert) lawyers themselves relative to other experts and those in the 'foreground' let alone those offering resistance legally or otherwise. Throughout the book, there are repeated and welcome qualifications to the hypotheses concerning the nature, the powers and the (ill) effects of the international lawyers in making international law. No doubt, such legal shenanigans and their impacts are not confined to the US but there is a case for its having been much more prominent as the leading power in specifying the legalisation of the global. In short, by implication, international law is built upon and is conditioned by neoliberalism, underpinned by financialisation, and reflects a shifting individual content and mutual interaction of scholarship, ideology and practice.

\section{FROM TWO POLITICAL ECONOMIES TO REREGULATION?}

In general terms, the book in principle seeks to frame recent developments in a political economy of two different types, which may not even be compatible with one another (let alone with performativity). The first is through the idea of capture of distributive rents, along global value chains for example. ${ }^{45}$ The second is through presence of developmental (or not) backwash effects by reference to Gunnar Myrdal. ${ }^{46}$ Now the latter is deeply committed to specifying the structures, agents, relations and processes by which change comes about. It is much more general than the those-who-gain-rents-must-defeat-those-who-lose-rents approach

\footnotetext{
${ }^{45}$ Kennedy (2016) 179-87.

${ }^{46}$ Ibid 202-07.
} 
which is both limited to distributional gains and losses (and, for my principles of political economy, too ready to 'rentify' disparate phenomena) and, crucially, is thereby rendered incapable of addressing how and why new or strengthened interest groups emerge (as opposed to its usefully identifying potential gains/losses from conflict/cooperation of interest groups that already exist). Thus, for example, straying far beyond my own expertise, how do we legally or otherwise identify the rents of terrorist groups in advance to ensure that they do not emerge or are negotiated into a cosy deal as liberation movement? More germane to my own work is to understand the rise of financialisation as a particularly powerful (if now frontloaded) backwash of the collapse of the postwar boom, strengthening and creating new financial elites rather than simply rewarding them.

And, in short, whether with finance or otherwise, in the global political economy the building of systems of international law is based upon a combination of structures, relations, processes and agencies of which expertise is, at most, a discursive part however fully and influentially engaged. How this works out might best be understood through a material culture of law which sees it as subject to the 10Cs, introduced above: Constructed, Construed, Conforming, Commodified, Contextual, Contradictory, Closed, Contested, Collective and Chaotic-I confess this is an extrapolation from an approach first developed for understanding the material culture of private consumption although it has been extended to a number of other applications such as ethics, identity, public provisioning and well-being - so why not international law as well. ${ }^{47}$ How the $10 \mathrm{Cs}$ are combined with one another, and attached to material structures, relations, processes and agencies, is liable to vary from one application to another but an exclusive pre-occupation with, as opposed to a situating of, legal expertise is liable to be too narrow.

Let me begin to finish, though, on a personal and indulgent note. I hope to have managed to cure myself of what was once an obsessive inclination to criticise social capital. One aspect of the literature has been its total confinement within the national, in part a reflection of the failure to consider the social capital of the powerful, even at a national level let alone the globally organised elites. But, across tens of thousands of contributions on the topic, there was just one of a handful that has addressed such global social capital - a case study of the social capital of international lawyers, predominantly both American and male. ${ }^{48}$ As I put it:

Dezalay and Garth ... argue that through the functioning of international law, large US law firms and law schools comprise legal and social capital (political connections) that lead to the Americanisation of laws to the advantage of US economic and, it should be added, political power. ${ }^{49}$

Much the same must be true of the world of finance on which I have placed so much emphasis. Yet, Kennedy's book together with, I suspect, the academic discipline of law,

\footnotetext{
${ }^{47}$ See, e.g., B Fine, 'Political Economy for the Rainbow Nation: Dividing the Spectrum?', South African Sociological Association Conference, 28 June-2 July 2009, University of the Witwatersrand, Johannesburg, available at http://eprints.soas.ac.uk/7972/1/sasa benfine.pdf (last visited 14 April 2016); B Fine 'Economics Unfit for Purpose: The Director's Cut’, SOAS Department of Economics Working Paper No. 176 (2013), available at https:/www.soas.ac.uk/economics/research/workingpapers/file81476.pdf (last visited 14 April 2016); B Fine, 'The Continuing Enigmas of Social Policy', UNRISD Working Paper No. 2014-10 (2014), available at http://www.unrisd.org/Fine (last visited 14 April 2016); Fine, 'Consumption Matters' (2013). ${ }^{48}$ The lack of gender in the book is taken up in the companion piece by Gina Heathcote.

${ }^{49}$ B Fine, Social Capital versus Social Theory: Political Economy and Social Science at the Turn of the Millennium (Routledge, 2001) 123, citing Y Dezalay \& B Garth, 'Law, Lawyers and Social Capital: "Rule of Law” versus Relational Capitalism’ 6(1) Social and Legal Studies (1997) 109.
} 
unlike the rest of social science (other than, perversely, mainstream economics and social policy), has proceeded as if financialisation simply does not exist. Surely, in defining contemporary international law, it sits as an imperative in the wake of 1648 ?

Consider, for example, the following account of financial regulation drawn from Andrew Haldane - who is now Chief Economist at the Bank of England, previously responsible for financial stability. He reports that Basel I at 30 pages in 1998, went to 347 pages in Basel II in 2004, and stood at 616 pages with Basel III in 2010. ${ }^{50}$ For the USA, the Glass-Steagall Act in 1993 took just 37 pages compared to the 848 pages of the Dodd-Frank Act of 2010 (with 400 bits of detailed rules for regulatory agencies), with a further 8,843 pages for the rulebook in covering just one third of the rules involved. Even more striking is the (employment) burden of financial regulation with one UK regulator for 11,000 financial sector employees in 1980 compared to one for every 300 today, with fewer than 100 increasing to over 3,000 regulatory employees involved. By the same token, in the USA, with 18,500 regulatory employees for finance, this provides three regulators for each US bank. On the other hand, demands on UK banks to meet reporting requirements have gone from 150 entries in regulatory returns to 7,500 items of data, with new European rules possibly requiring a total of over 30,000 entries over 60 different forms. Just to meet Basel III compliance, over 350 European banks, is estimated to support 70,000 new jobs.

Of course, this will not happen, and the reregulation of finance is more observed in the breach (witness the New Yorker cartoon showing two lawyers agreeing that such new regulations will totally transform the way they get around them). No doubt, such regulatory conundrums could be seen as the playthings of economists as they go about making markets, or the playthings of the legal experts as they go about making international (financial) law-I leave it up to them to fight out which performer gets top billing or perhaps expert economists are also lawyers in all but name, and vice-versa. But my more serious intent would be to ground our understanding of the role of experts more fully and concretely in the specific activities to which they are closely attached as well as the broader context in which they are situated and with which they are mutually determining rather than serving as primary let alone sole determinant. We could even begin with good old American empiricism: who are they, in what fields, who trains them, how much do they get paid, who employs them, and how has this all changed, especially under financialised neoliberalism and the New World Order? Follow the money and you might find that the experts of international law are no different from the politicians they serve (or is it vice-versa, once more) - these are my principles and if you don't like them, I will change them.

In short, whatever the best intentions of legal experts in the area of international finance, proposals for reregulation are structurally and contextually delimited by the nature and situation of global and national finance. That is surely as, if not more, important as the legal experts in the making of international law with similar, if hardly identical, structures, agencies, relations and processes prevailing across the makings and influences of international expertises more generally.

\footnotetext{
${ }^{50}$ The Basel accords are a set of recommendations for banking regulations, issued by the Basel Committee on Banking Supervision.
} 